\section{$\underset{\substack{\text { hommes } \\ \text { \& migrations }}}{ }$}

\section{Hommes \& migrations}

Revue française de référence sur les dynamiques

migratoires

$1300 \mid 2012$

Nouveaux modèles migratoires en Méditerranée

\title{
Marc Bernardot, Captures
}

Éd. du Croquant, 2012, 189 pages, 11 euros

\section{Brice Arsène Mankou}

\section{(2) OpenEdition \\ 1 Journals}

\section{Édition électronique}

URL : http://journals.openedition.org/hommesmigrations/964

DOI : 10.4000/hommesmigrations.964

ISSN : 2262-3353

\section{Éditeur}

Musée national de l'histoire de l'immigration

\section{Édition imprimée}

Date de publication : 1 novembre 2012

Pagination : 168

ISSN : 1142-852X

\section{Référence électronique}

Brice Arsène Mankou, « Marc Bernardot, Captures », Hommes \& migrations [En ligne], 1300 | 2012, mis en ligne le 01 novembre 2012, consulté le 22 septembre 2020. URL : http://journals.openedition.org/ hommesmigrations/964; DOI : https://doi.org/10.4000/hommesmigrations.964

Ce document a été généré automatiquement le 22 septembre 2020.

Tous droits réservés 


\title{
Marc Bernardot, Captures
}

\author{
Éd. du Croquant, 2012, 189 pages, 11 euros \\ Brice Arsène Mankou
}

\section{RÉFÉRENCE}

Marc Bernardot, Captures, Éd. du Croquant, 2012, 189 pages, 11 euros

1 L'ouvrage de Marc Bernardot porte un titre étrange. "Captures est le résultat de plusieurs années de recherches sur la question des politiques migratoires en Occident." Dans la première partie, l'auteur rappelle les captures pratiquées dans un contexte de violence où l'État et le corps social déclarent la guerre à l'étranger et, dans une large mesure, aux migrants et aux minorités. Ces pratiques érigées en système se manifestent selon lui par des types de "surveillances spécifiques, d'internement administratif, de brutalisation dérégulée, des contrôles, des arrestations arbitraires et détentions illégales groupées, etc." La deuxième partie est consacrée aux ruses du marché fondées sur une forme de privatisation des guerres de capture et une théatralisation des opérations avec ce qu'il appelle "les armées de confort". L'auteur souligne, par exemple, que "le modèle français de la privatisation de ces secteurs névralgiques relève d'un caractère hybride dit du "partenariat public-privé, déjà largement testé en Grande-Bretagne. Le résultat est néanmoins le même." Il évoque des entreprises qui participent à la privatisation des guerres de capture.

2 Les catégories de "sans-papiers", de "clandestins" connaissent une précarisation administrative et socio-économique commune qui facilite ces captures alors que plusieurs secteurs en tension risquent demain de se retrouver sans main-d'œuvre. Les ruses du marché se multiplient et ces catégories déjà fragilisées restent "disponibles, désirables et déportables".

3 La dernière partie de l'essai revient sur cette culture de la chasse et du camp. Alors que le monde devient "un village planétaire" avec des mobilités Sud-Nord, et de plus en plus Sud-Sud, et Nord-Sud, la chasse à l'étranger interroge la citoyenneté transnationale dans un contexte de migration mondialisée. Cette culture de la chasse à l'étranger vise à éliminer la visibilité des migrants dans l'espace public. Avec la 
circulaire Guéant du 31 mai 2011, le monde universitaire a été lui aussi touché par la politique de captures et de rafles. Depuis 2003, le ministère de l'Intérieur a fait de la capture des étrangers un axe fort de sa politique. Il s'agit de mettre hors de France ce que Marc Bernardot appelle des "illégalisés". Au moment où cette politique de captures brise des vies humaines, les expulsions obéissent à une logique décrite par Olivier Le Cour Grandmaison à travers un tryptique : "Traquer, interner, expulser ${ }^{1}$."

Depuis des décennies, le contrôle des frontières et de l'accès à la citoyenneté ont été considérablement renforcés en Europe et ailleurs. Alors même que s'accélère un puissant processus de globalisation, les mobilités humaines sont pour partie entravées. Les entraves se multiplient par les consignes données aux préfets d'assurer ces contrôles. Marc Bernardot s'inscrit sur la longue liste de ceux qu'on peut appeler "les indignés de l'Etat de droit". Ces intellectuels indignés utilisent leurs écrits pour dénoncer l'arbitraire et les injustices que vivent les migrants.Dans cette optique, Captures est engagé. Le sociologue utilise son terrain pour dénoncer l'intolérable et analyser les conséquences sur le "vivre ensemble". Il scrute notre société qui affirme les principes républicains sans jamais s'interroger sur les captures qui constituent une antithèse de la liberté. Il dénonce aussi les discriminations qui sont un poison contre l'égalité et les expulsions qui contredisent la fraternité. De ce point de vue, il a tenu à montrer les limites de cet État dans sa capacité à protéger ces "illégalisés". Au tryptique "Traquer, interner et expulser" pourrait se substituer dans un État de droit "Accueillir, protéger et maintenir" dans une Europe qui demain devra importer des migrants pour faire vivre ses territoires. L'ouvrage s'interroge sur l'altérité et la place de l'étranger dans un continent vieillissant qui, selon les démographes, aura recours plus systématiquement aux captures dans des sociétés pourtant dites "civilisées".

\section{NOTES}

1. Olivier Le Cour Grandmaison (dir.), Douce France. Rafles. Rétention. Expulsions, Paris, Seuil, 2009. 